\title{
NEW ERA GATHERING MATHEMATICS AND ARCHITECTURE
}

\author{
Saeedeh Dehghani Najhvani \\ Department of Architecture and Urban planning, Isfahan (Khorasgan) Branch, Islamic Azad \\ University, Isfahan, Iran \\ sd lotus@yahoo.com
}

\author{
Bahram Shahedi \\ Associate Professor, Department of Architecture and Urban planning, Isfahan (Khorasgan) Branch, \\ Islamic Azad University, Isfahan, Iran \\ bshahedi@khuisf.ac.ir
}

\begin{abstract}
In this study,it has been tried to recognize the facilities of digital environment which has emerged a new literature in creating architecture works, by recognizing the world of digital analyzing consisting for motion of imaginations and illusions of architects and the discussions relating to building and indicating technical details and performing steps and various analyses. Research method in this study,is qualitative and kind of analytical-descriptive and the general method of data collection is the type of literature Regarding the studies made in this field this literature begins from the primary steps of concept design and ends to the step performing a building project.in the design step,one can make analyzes and various assessments using computer environment and algorithmic base in a short time and by the least cost.digital structure and production is the last step of the process of digital design and production in which wing of proper equipment and hardware is inevitable.from the view point of cohesion the process of digital design and structure, what is important is the way of connection of designing soft wares to these hard wares(structure machines).in the conclusion, we introduce the mathematics and algorithmic patterns and the way of using them and applying them in some case samples.the findings showed that patterning and designing with computer soft wares and using the algorithms cause enabling in design and industrial production of buildings and we todays with nesses that creativities in using the materials and new ones of them has been emerged by digital facilities,simply,new formations would be designed then built and survey would be done on them by using the algorithm of the relation between the materials and the methods.
\end{abstract}

Keywords: Digital architecture, Algorithmic, designing digital, structure mathematics, modern architecture

\section{INTRODUCTION}

industry civilization occurring with industries revolution and by relying on scientific advances in various fields of life, represented a new way of life to industry societies. and defined a new frame of life to people. Toffler called it regulation of industries societies. the regulations had changed all fields of life of people and caused some subjects in industrial societies[1].in a way that now it is for several years that computer is serving human kind as a powerful calculator machine and it does complicated and long time works in each field instead of man computer works as a calculator in medicine, military, geography, aviation, engineering, entertainment and every corner of science and technology and it gives us tools and facilities in a that today. world is dependent to computers for doing the simplest bank operations and controlling marc aircrafts according to what mentioned, it's desired to know that this technology advance has any effect on architect as well, or not the emerge of the new lifestyle based on machine and industries production, affected by deep cultural influences caused by big changes and developing trans formations in life of man culture and the components was fully changed facing with the new system, and new values governed on society, as we know, through the history, the 
architecture has been the epitomizer of the tendencies of the society and there's a deep relationship between the architecture and the changes. Architecture influenced by the changes exposed on the society, has changed a lot one of the most important effects is seen now in the present age and the communication age. now that developing application of computer and inventing internet is governing has created on important age in the developing process of architecture it has been for a long time that we witness existing samples of architecture projects which are not sorted and known by old titles of past decades, the se project, which are known by titles such parametric and algorithmic architecture, are originated from new process of design that seem the role of computer was so important on them and it plays a major role beyond a mere simple machine[2]. what is seen today and in updated projects of architecture is serving computer by algorithms, codes and programs. the resulted architecture, can so involve environmental, historical, regional, cultural parameters as a product since it is dependent on the various items and parameters in the process of production and reply to them by controlling and leading the design. now we want to know how advanced and progressive alga remind mathematics make changes in the way of thinking of architects to space designing and method of designing modern architect and structuring them caused an emerge of a new age of architecture design titled algorithmic design and parametric architecture[1].research method in this study is qualitative and anal, descriptive and the method of data collecting is typed librarian[3].

Fig.1

\section{ALGORITHMS IN DIGITAL DESIGN}

in this stage should answer some questions. what is algorithm? Algorithm is $\mathrm{n}$ identified set of clear orders in a series that can do determined operation, algorithm is the process of problem solving like following some instructions it is in fact solving problems in a wronged, ordered was in order to generalize that to similar problems[4].simply it is similar to making a food steps of making a food steps of making a food are providing raw materials, preparing them, mixing them cooking and serving the food clearly in this instruction, the number of demanded food, the amount of it, quality of raw material and order and time of each step affects the final product if the order of making a food is conversed, or one step added or least, there would be anew algorithm that leads another result. the changes can lead to a better results or a similar result and also could lead to a worse result. however changing the order of steps and using random variables in a process. could lead to solvation's that are not only no well know but also in considerable difference with the original purpose of the design. why algorithms are important although an algorithm can determine the way of doing sth in a written why and determine a common rule in this term for doing an operation for us but in fact it is done by changing it to codes and determined leg of programming and performing in the computer, the powerful calculator of computer and it's speed and accuracy so we can transfer bulks of complicated calculation with necessary orders to computer and just wait for accurate fast replies how algorithms can help to design algorithms in award definition, is a set of step by step order that can do all calculations and operations in programming language so it can burn mange activates designing to instructions and give data be computer to do the operation in this term we can say instead of drawing the whole components of the design, one can transfer data for the need of the design in an order way to he computer for making done in this step, the designer has the opportunity to make form using coding and programming if in the past designing forms in 3D programs was done by structuring and editing one by one of blocks directing by user connection of these software's and choosing the available blocks in libraries, now new software's provides the possibility of algorithmic development of from in designing space so that by programming the form, the new revolution of digital in design field emerge[5].

\section{Fig.2}

Algorithm a determined set of orders that receive the data as input, then process it and finally replies as an out put. the designer can define data another way it comes to algorithm and the way of process by the algorithm. the result of this process would be shown as a form in the virtual space in this 
process depending on the need of designer, one or hundreds of factors would be designed and edited and in virtual space as a result, designer in this process is not busy with producing predefined form he/she sets a series of rules and organize an algorithm that based on processing that, the architectural form is made so we mag say that architectural form is not the only main topic, but the process of making that is under control of architect. in this process all the parameters affecting on design an forming space is exposable on algorithm and architecture is formed in a space influence by various parameters affecting on project and the definition of the way of effectiveness architects and designers can brief the most complicated spaces in an algorithmic way and turn the space complicatedness to calculative cumulativeness and control the conditions intelligently by themselves by transferring that to computer that has high calculating power and by information management and understanding and exposing the various effective parameter on architecture, progress the design in the virtual space[2].

\section{DESIGN IN THE VIRTUAL SPACE COMPUTATIONAL GEOMETRY}

the combined knowledge of computational geometry is as branch of computer that studies algorithms with geometrical function actually for solving geometrical problems it use algorithmic solvation's and has various applications in field of robotic, geographies in formation system, complex axis design, designing and forming digitally, communications, cellphone are so on it help designers in so many fields finding geometrical solve for questions having more than one correct answer and improving algorithms to find the best answer are the main use of that or searching for architecture solvation's in which there were numbers of effective factors on design and based on scaling those factors, the find assessment should be done. it can act from the primitive design to the details[6].

\section{Fig.3}

\section{GENERATIVE ALGORITHMS}

computational geometry consists of a developing circle of algorithms that can be replying to geometrical needs of various fields of science but clearly, generative algorithms are the ones which the capability of making reply design with algorithmic methods and use them they cover special problems for space design and architecture in CAD software in combining with facilities and ordered[2]. As an example, can name mosaic or tile algorithms that can device a surface to thinly divisions and the repetitive element is again increased and increased on the surface on the mosaic these algorithms in architecture of surfaces that the form of components in creasing change, little by and is follower of arch of the plates are so usable. in the following we explain cases of the most usable generative algorithms findings this classical structure of forming in a research study was survey and assimilated in an algorithmic space the purpose was that cache plate form was to weave in the design space wising this algorithm by the fabrics. for the fabrics no matter size or material algorithm could weave the fabric with simple patterns or complicated ones. it acts as a common pattern of designing and the product is created as a geometrical form in the virtual space in the next stages, this product could be in different was, and with the definition of size mater and find form in the profile of building, ceiling, in eternal cover, and the separator.

\section{Fig.4}

Spongy shells: in a research study on developing and designing the building spongy shells, a generative algorithm for making a system based on a biological pattern was studied in this project, first the features of form, shape, structure and geometry of radiolarian a one-cell creature was studied since the spongy shell of this creature studied in other research's, various potentially in forming the structure were modelled in this project it tried to study the process of forming this shell in nature and assimilated in algorithmic space this process was planned in some stages. the result was developing an algorithm which could divide the plates with free forms based on geometrical odes of this organism made hole in it so that a sponge come out at the end, we used other alternative algorithms to formation job so that the shell would be formed by the systems based on even part and laser cutting technique the 
result of this process was to design and produce a shell that was formed based on different factors in this research project, we used different algorithms to as simulate design and formation of a shell that can be applied in architecture the branch of covers in future[7].

Strips: systems based on strips use tong, thin plates and make them resistant as well as a geometrical, regulated structure these systems that could use waste and recycles in some cases turn non resistant trifle to a system which can have functions like plates, walls and covers[2].

\section{OPTIMIZATION DESIGN}

Optimization is the complex point of the design circles analyze in this method, there has been imaged determined conditions for a good architecture and by repetitive design and analyze one or some recommended design optimize that design to match with good concentrating on one choice and choose the best choice by looking at possible ones.

optimization, is a activity in repetitive circles in each of round these circles, desirable choices are formed by optimizing the former ones and one some of them that are better would be chosen these choices are of ten great archi forms and organization that finally lead to designing the components by choosing a find choice.

\section{Fig.5}

Architecture design processes always are able to present more than one solution for a certain question. designers in most cases present choices for design so that they can choose the best choice by seeing the pros and cons optimization also is used in conditions that its possible to present more that one answer so it needs to be optimized the criterion used to optimize architecture maybe not always quantitative but architects try to turn the concepts effective on design to digital qualities optimizable through algorithmic way optimization could have useful functional in replying to environmental factor, in eternal ecosystems, near to the building. distribution of operational system of the building preparing the scheme for build however the process of design based on digital building. consists ethnics and methods that in the past years. have had developed a lot considerable part of these methods and techniques depends on the type of work and digital machines mechanism[8].

\section{ALGORITHMS IN DIGITAL BUILDING}

we can name a product process digital, just when the techno's used in that process have a automatic relationship between computer model and digital formed of the product and process on one hand and the stage of production on the other hand. it means in the process of production, these is no need to human existence as the render factor or interpreter of digital model for the machine. the process can involve extensive board of activities. this range could consist producing trivial pieces of a building to assembling the main parte of a building for achieving the final form. maybe in some cases, a process would not be digital totally and part of it should be done by human but other parts done by computer and equip mental. also maybe in a process and digital production man works in order to control the process of design, production, monitoring and even in some cases leading also to digital process meaning full, performing it must be necessary and justifiable this justification can bee getting the work done in shorter time or economizing that and lowering the costs or increase the accuracy this point is so important in the digital production processes because in case that using the digital technology doesn't lead to optimization of the product qualitative or quantitative applying that would be turned into just an unnecessary and formal apply the history of emerging digital production he world of analyzing digitally came out to help design for architecture near since 1960. at that time projects like Sydney porch house were at the stage of design and for modelling and programming it performing was computer equipment's seemed necessary little by little by raising facilities coming to the field of architecture design has changed a lot and forms had been led to shapes that mostly had no restrictiction in building them[5]. 
Fig.6

the first questions rising is that how design and performing such projects are made or actualization of surfaces and fee archs show in these designs are possible by which tools[5].

Digital architecture modern tools of computer, as simulate projects and designed them that before that with classic methods was not possible these works have brought a lot of variety to the building industry at a short time found a posited in business world however from the beginning, the structuring, the main challenge facing that archi and for complexity and impossibility of building may of these projects caused critic in such a way that conservative criticizers introduced this kind of archi, appropriate for magazines that can just illustrate beautiful images but can not turn into reality (journal architecture) although few architects gradually tried to perform some of their projects but the challenge of build apposed to digital flow of archi was so serious. modern archi needed new tools for being done. in these conditions a curate tools could be a proper reply to this subject in development of parametric archi, the topic of digital building was important as designing digitally and helped it's growth now we want to study the subject in terms of history tools ad methodology[2].

\section{NUMEROUS PRODUCTION IN MODERN ARCHITECTURE}

one of the effective factors on creating the idea of modern architecture was industrial revolution that created the new methods of structuring and presented solutions available with occurring industries revolution, new protectors and also new problems emerged and caused creative and sensitive ergative recording to the current needs[9].in this regard modernism brought about an important idea: pre structuring and numerous production of buildings. idea of building numerously, in modern industry that came out from industries like automobile came to the building structures building in modern architecture should have assembled numerously in separate parts besides all the virtues and flats of technique of pre structuring a vital question raised should the buildings and the parts be so repetitive and similar to this extent these gray, big, boring buildings were missing quality of prettiness and statured projects like this gradually caused criticism of all people although for countries numerous structuring and cheap housing was so proper but these buildings and borings complex gradually turned to places with social problems for livings of the people and typically caused a fault of idea of numerous structuring of residents complexes and modern living so that would become, symbol point of death of this type of buildings solutions that industry found against the problem gradually turned back the positive points of numerous structuring to he construction[2].

\section{CUSTOMIZATION NUMEROUSLY}

concentration on personalize the goods in inducting and combine with the flow of numerous production, ident of mass customization came to produce goods and services[10].mags customization means producing customized goods numerously by digital machines these system can combine low prices and positive points of production with flexibility potential in digital production and produce ports and customized goods for different people frank pillar finds mass customization the design process of product with help of customer in away that the needs of that customer would be met regarding the variable item in those goods the believes that this process would be done in a determined space but flexible mass customization formed an idea by providing similar parts digital machines and maybe it leads architecture which was not successful in mass production to mass production of customized goods. this subject way connected to current archi and the result, way merging a new method of archy in a digital production and design combination model[2].

\section{DESIGN TECHNIQUES FEW DIGITALIZATION}

one of the most issues in archi (digital) is considering the parameters of production, from the beginning of the process and registering these parameters controlling in design algorithms. in such a way that the product would have the capability of being produced in fact the designed form could be influenced by the structuring factors from the beginning so that any move, tubist or bending, size or what ever face the stuttering with problems would be eliminated[11]. 
So that the final form based on these criterions would have the capability of bang structured also for exposing deformation seemingly in opposed to economy of the project, today been turned into a realistic path from a future idea by the changes raised from mass customization facilities and processes of digital structuring and the experienced experts have the ability to build so complicated buildings. these facilities not only have the capability of structure but also define the ways of structuring for future digital structuring is a process in which they use machines and equipment's digitally for producing for producing parts needed for a project they use types of digital codes provided by digital design process for updated designees. this project is as important as digital designing since the tendency for the beauty in the current world is leading increasingly to use complicated elements and having problem in produce in classic way so turning complexity of the process to digital machines can be a smart decision in such conditions. design in digital places with all the formation complexities is done and the structure stage leads to accurate (digital) machines and turn the building construction from an with low level technology to a high level one some techniques and methods of working digitally are techniques based on cutting material increasing material decreasing them ways of deformation using absorption and heat that each is proper for machines that do the related job in the process of structure and production according to these techniques different methods of designingly modelling the parts are developed to ply for the needs of the construction part the designer prepare the files related to needs of digital machine and begin to structure after ending the sign stages and preparing parts to exon case studies a ate end, we try to know the modern archi buildings and have the discussion of applying algorithms in design structuring or both and postpone saying how to use it modelling and design by software's depending on algorithms cause capability in design as well as industrial production of buildings. today we witness creative we forms are designed then come out of and tested by also of the relation ship between material and methods one of the advantages of this system is to test persistency and functions of material by assimilating and modelling the form before building that leads to observe each scheme before building it form and space in past archi have just one answer that commonly has no second answer for design parts and collaboration of different forces forming form and space enable forms. morphology comes typology for grouping answers possible so according to new function of design and product digitally we can forget classic methods[8].

\section{INTRODUCING CASE STUDIES}

\section{ALIANZ ARENA STADIUM}

The stadium construction began on 21 October 2002 and was officially opened on 30 May 2005. The primary designers are architects Herzog \& de Meuron. The stadium is designed so that the main entrance to the stadium would be from an elevated esplanade separated from the parking space consisting of Europe's biggest underground car park. The roof of the stadium has built-in roller blinds which may be drawn back and forth during games to provide protection from the sun.

Fig.7

- Total concrete used during stadium construction: $120,000 \mathrm{~m}^{3}$

- Total concrete used for the parking garage: $85,000 \mathrm{~m}^{3}$

- Total steel used during stadium construction: 22,000 tonnes

- Total steel used for the parking garage: 14,000 tonnes

- The first of its own digitalization design process

\section{EDEN PROJECT GARDENS}

The project was conceived by Tim Smit and designed by architect Nicholas Grimshaw and engineering firm Anthony Hunt and Associates (now part of Sinclair Knight Merz). 
Davis Langdon carried out the project management, Sir Robert McAlpine and Alfred McAlpine did the construction, MERO designed and built the biomes, and Arup was the services engineer, economic consultant, environmental engineer and transportation engineer.

Land use consultants led the masterplan and landscape design. The project took $2 \frac{1}{2}$ years to construct and opened to the public on 17 March 2001.

The Core is also home to art exhibitions throughout the year. A permanent installation entitled Seed, by Peter Randall-Page, occupies the anteroom. Seed is a large, egg-shaped stone installation displaying a complex pattern of protrusions that are based upon the geometric and mathematical principles that underlie plant growth inwich all these forms are provided throw many digital occupation and analyzers of its own time in mathematics and design process.

\section{Fig.8}

\section{JEAN MARRY TIJIBAO BY RENZO PIANO}

The building plans, spread over an area of 8,550 square metres $(92,000 \mathrm{sq} f \mathrm{ft})$ of the museum, were conceived to incorporate the link between the landscape and the built structures in the Kanak traditions. The people had been removed from their natural landscape and habitat of mountains and valleys and any plan proposed for the art centre had to reflect this aspect. Thus, the planning aimed at a unique building which would be, as the architect Piano stated, "to create a symbol" ..."a cultural centre devoted to Kanak civilization, the place that would represent them to foreigners that would pass on their memory to their grand children". The model as finally built evolved after much debate in organized 'Building Workshops' in which Piano's associate Paul Vincent and Alban Bensa, an anthropologist of repute on Kanak culture were also involved. The precursor for this cultural centre was the first cultural festival held in 1975 in New Caledonia, which was a focused celebration of Kanak culture. The Melanesia 2000 Festival was also held at the same venue where the centre has been established now. The centre is also termed as "A politicized symbolic project", which evolved over long period of research and intense debate.

Another aspect of the Kanak's building tradition was that it did not fit in with the concept of a permanent building. They lived in temporary type of buildings made with locally available material which needed to be replaced from time to time in the subtropical climate. This involved a wood frame building built on earthen plinths and with roof covered by thatch. The form of the building also varied from island to island, generally round in plan and conical in the vertical elevation. They made the houses in groups with the headman's house at the end of an open public alley formed by other buildings clustered along on both sides. Trees lined these alleys with a shady central gathering. This theme was adopted in the Cultural Centre planned by Piano and his associates.

An important concept that evolved after deliberations in the 'Building Workshops', after Pinao won the competition for building the art centre, also involved "landscaping ideas" to be created around each building. To this end, an "interpretative landscape path" was conceived and implemented around each building with series of vegetative cover avenues along the path that surrounded the building, but separated it from the lagoon. This landscape setting appealed to the Kanak people when the centre was inaugurated. Even the approach to the buildings from the paths catered to the local practices of walking for three quarters of the path to get to the entrance to the Cases. One critic of the building observed: "It was very intelligent to use the landscape to introduce the building. This is the way the Kanak people can understand".

\section{Fig.9}




\section{SYDNEY OPERA HOUSE}

Stage I commenced on 2 March 1959 with the construction firm Civil \& Civic, monitored by the engineers Ove Arup and Partners. The government had pushed for work to begin early, fearing that funding, or public opinion, might turn against them. However, Utzon had still not completed the final designs. Major structural issues still remained unresolved. By 23 January 1961, work was running 47 weeks behind, mainly because of unexpected difficulties (inclement weather, unexpected difficulty diverting stormwater, construction beginning before proper construction drawings had been prepared, changes of original contract documents). Work on the podium was finally completed in February 1963. The forced early start led to significant later problems, not least of which was the fact that the podium columns were not strong enough to support the roof structure, and had to be re-built.

The shells of the competition entry were originally of undefined geometry, but, early in the design process, the "shells" were perceived as a series of parabolas supported by precast concrete ribs. However, engineers Ove Arup and Partners were unable to find an acceptable solution to constructing them. The formwork for using in-situ concrete would have been prohibitively expensive, and, because there was no repetition in any of the roof forms, the construction of precast concrete for each individual section would possibly have been even more expensive.

The design of the roof was tested on scale models in wind tunnels at Southampton University and later NPL in order to establish the wind-pressure distribution around the roof shape in very high winds, which helped in the design of the roof tiles and their fixtures.

The shells were constructed by Hornibrook Group Pty Ltd. who were also responsible for construction in Stage III. Hornibrook manufactured the 2400 precast ribs and 4000 roof panels in an on-site factory and also developed the construction processes. The achievement of this solution avoided the need for expensive formwork construction by allowing the use of precast units (it also allowed the roof tiles to be prefabricated in sheets on the ground, instead of being stuck on individually at height). Ove Arup and Partners' site engineer supervised the construction of the shells, which used an innovative adjustable steel-trussed "erection arch" to support the different roofs before completion. On 6 April 1962, it was estimated that the Opera House would be completed between August 1964 and March 1965.

Stage III, the interiors, started with Utzon moving his entire office to Sydney in February 1963. However, there was a change of government in 1965, and the new Robert Askin government declared the project under the jurisdiction of the Ministry of Public Works. Due to the Ministry's criticism of the project's costs and time, along with their impression of Utzon's designs being impractical, this ultimately led to his resignation in 1966 (see below).

\section{Fig.10}

\section{PARASOL METROPOLIS}

The structure consists of six parasols in the form of giant mushrooms ("Las setas" in Spanish), whose design is inspired by the vaults of the Cathedral of Seville and the ficus trees in the nearby Plaza de Cristo de Burgos. Metropol Parasol is organized in four levels. The underground level (Level 0) houses the Antiquarium, where Roman and Moorish remains discovered on site are displayed in a museum. Level 1 (street level) is the Central Market. The roof of Level 1 is the surface of the open-air public plaza, shaded by the wooden parasols above and designed for public events. Levels 2 and 3 are the two stages of the panoramic terraces (including a restaurant), offering one of the best views of the city centre. 


\section{CONCLUSION}

Nowadays $\mathrm{T}$ its very common to use the capability of softwares and to register some ideas throw the cadre of mathematic solvations.its so often recognized that the algorithmic and computational masses are so easier to solve rather than with ancient design methods.with new digital abilities new forms are designed and took out of the whole body platforms and throw the algorithmic periods go to shape the final result.the basic advantage of this method is its precasting ability that gives us several choices and for each one an amount of answers.the form and shapes in traditional design methods were defined with just one unique result but the result in modern digitalized design process is vary depending on basic informations . ghatering the form and the information in which shapes the form in this type of design process is one of the most important advantages of its own.so that, here is the family of forms that is important and typology and morphology are rising to answer as many as questions they can.so with this site of view it could be possible to create a new strategy and pathway throw the design process and also the fabricating and prebuilding types of new era.

\section{REFERENCES}

Ahmadi,saeid.Vafamehr,Mohsen(1391).Rules of industrial societies and modern movement in architecture.sakhte shahr,Tehran.

Khabazi.zubin(1391). Digital design processes, Kasra Publication.

Abbasi,Zahra(1389). Computer algorithms on digital architecture, rah-o-sakhteman international mag,Vol 8,76.No.

Sipser, Michael (2012).Introduction to the Theory of Computation,Third Edition, Cengage Learning Publishing.

Golabchi,Mahmood,andgi garmaroodi,ali and bastani, hossein(1391). Digital Architecture, Tehran Pablication.

Berg ,Mark de , Van Kreveld , Mark , Overmars , Mark(2011).Computational Geometry ,Third Edition.

Khabazi ،Zubin (2012) Generative Algorithms, Cocept and Experimants: Porous Shell.

Khabazi.zubin(1393). "Algorithmic Architecture Paradigm", Kasra Publication.

Curtis ‘William J.R. (1983).Modern Architecture Since 1900 ، Prentice-Hall Publishing, Second Edition.

Piller ‘Frank (2013) Mass-Customization.

Hensel, Michael, Manges, Achim (2006) Morpho-Ecologies, Architectural Association. 